\title{
Poly(anthraquinonyl sulfide) Cathode for Potassium-ion
}

\section{Batteries}

\author{
Zelang Jian ${ }^{1 \#}$, Yanliang Liang ${ }^{2 \#}$, Ismael A. Rodríguez Pérez ${ }^{1}$, Yan $\mathrm{Yao}^{2,3^{*}}$, and Xiulei $\mathrm{Ji}^{1 *}$
}

1. Department of Chemistry, Oregon State University, Corvallis, OR, 97331-4003, United States

E-mail: david.ji@oregonstate.edu

2. Department of Electrical and Computer Engineering and Materials Science \& Engineering Program, University of Houston, Houston, Texas 77204, United States

3. Texas Center for Superconductivity at the University of Houston, Houston, TX 77204, United States

E-mail: yyao4@uh.edu

\# These authors equally contribute to the work.

\begin{abstract}
Potassium-ion batteries (KIBs) are a promising sustainable energy storage technology due to the high abundance and low cost of potassium. Carbon anode materials for KIBs have seen great successes, but the development of cathode materials is yet to catch up. In this study, poly(anthraquinonyl sulfide) (PAQS) is evaluated as a cathode material for KIBs. It exhibits a high reversible capacity of $200 \mathrm{mAh} / \mathrm{g}$, which is the highest value for a potassium storage cathode material. The cell shows two slopes averaged at 2.1 and $1.6 \mathrm{~V}$ vs. $\mathrm{K}^{+} / \mathrm{K}$. It shows a good cycling performance with the capacity retention of $75 \%$ after 50 cycles at a rate of $\mathrm{C} / 10$. These preliminary results indicate that PAQS is a promising cathode material for KIBs.
\end{abstract}

\section{Keywords}

Potassium-ion batteries; Organic material; Cathode; Polymer

\section{Introduction}


Modular electrochemical energy storage is the absent enabler for large-scale installation of intermittent wind and solar energy sources. Li-ion batteries (LIBs) suffer the intrinsic drawback of lithium rarity and uneven distribution in the Earth's crust [1-3]. Despite their tremendous successes in portable electronics and electric vehicles, LIBs are not sustainable to be employed for purposes like load leveling, smart grid, and microgrids. It is inevitable to pursue alternative electrochemical devices based on elements that are Earth abundant. Recently, attention has been paid to potentially low-cost alkali metal-ion devices, including Na-ion batteries (NIBs) [1-3] and K-ion batteries (KIBs) [4, 5]. Potassium-metal based devices, including $\mathrm{K}_{-} \mathrm{O}_{2}$ batteries [6] and K-S batteries [7] also attracted attention, and aqueous-electrolyte-based KIBs employing Prussian blue cathode and anode were investigated as well $[8,9]$. Non-aqueous-electrolyte-based KIBs present unique advantages compared to LIBs and NIBs [5]. For the anode side of KIBs, our group and others have revealed that many bulk carbons, including graphite, soft carbon and hard carbon, demonstrate good capacity, e.g., ca. $270 \mathrm{mAh} / \mathrm{g}$, high reversibility and good cyclability [5, 10-12]. The K-carbon intercalation compounds represent the most stable type compared to other alkali-metal-carbon analogues. For example, the stage-one Na-graphite intercalation compounds (GICs) cannot even be formed due to the lack of favorable energetics between $\mathrm{Na}$ atoms and graphene sheets. For the electrolyte, K-ion diffusion in electrolytes is known to be faster than do Na-ion and Li-ion. The main challenge for KIBs may come from the cathode side due to the large strain caused by the bulky size of K-ions if crystalline minerals are used as cathodes.

Despite the difficulty, encouraging results have been obtained for cathodes in KIBs. To date, a few cathode materials were investigated $[4,13,14]$. Eftekhari demonstrated a Prussian blue cathode, which delivered a reversible capacity of $\sim 78 \mathrm{mAh} / \mathrm{g}$ with excellent cycling [4]. Hu et al. and our group reported 3,4,9,10perylene-tetracarboxylicacid-dianhydride (PTCDA) as a cathode, which showed a reversible capacity of 130 $\mathrm{mAh} / \mathrm{g}$ in a voltage window of $3.5 \sim 1.5 \mathrm{~V}$ vs. $\mathrm{K}^{+} / \mathrm{K}[13,14]$. The journey to pursue suitable cathodes for KIBs has just started and more advanced cathode materials should be developed. Organic compounds had been wildly used as both a cathode and an anode for LIBs and NIBs due to their potentially low cost, renewability, and environmental friendliness [15-17]. Poly(anthraquinonyl sulfide) (PAQS) as a cathode for LIBs, NIBs and 
Mg-ion batteries presented a high capacity ( $200 \mathrm{mAh} / \mathrm{g})$ and good cycling stability [18-20]. It is intriguing to investigate the K-ion storage behavior in PAQS.

Herein, we synthesized PAQS by a very simple method and for the first time investigated its electrochemical K-ion storage properties for KIBs. The PAQS/K cells delivered a high reversible capacity of $200 \mathrm{mAh} / \mathrm{g}$ with a relatively stable cycling behavior.

\section{Experimental}

To the mixture of 1,5-dichloroanthraquinone $(2.77 \mathrm{~g}, 10 \mathrm{mmol})$ and sodium sulfide nonahydrate $(2.4 \mathrm{~g}, 10$ mmol) was added methylpyrrolidone $(25 \mathrm{~mL})$ under argon. The stirred suspension was heated under argon at $200{ }^{\circ} \mathrm{C}$ overnight. After cooling down, the mixture was filtered and washed with hot water and acetone untill the filtrate became colorless. The "cake" was dried under vacuum at $120^{\circ} \mathrm{C}$ for $16 \mathrm{hrs}$ to yield the product as brown powder $(2.0 \mathrm{~g}, 86 \%)$. Powder x-ray diffraction (XRD) analysis was carried out on a Rigaku Ultima IV Diffractometer with $\mathrm{Cu} \mathrm{K \alpha}$ irradiation $(\lambda=1.5406 \AA)$. The Barrett-Joyner-Halenda (BJH) porous size distribution was calculated using the adsorption branch of $\mathrm{N}_{2}$ sorption isotherms. Fourier transform infrared spectroscopy (FTIR) spectra were recorded on a Nicolet 6700 spectrometer (Thermo Electron). The morphology is examined by a FEI NOVA 230 high resolution scanning electron microscopy (SEM). The electrodes are composed of PAQS, Super P, and polyvinylidene fluoride (PVdF) with a mass ratio of 70:20:10. The slurry was cast onto $\mathrm{Al}$ foil and dried at $100{ }^{\circ} \mathrm{C}$ under vacuum for $10 \mathrm{hrs}$. Coin cells were assembled with potassium foil as the counter/reference electrode, a glass-fiber separator, and $0.5 \mathrm{M}$ potassium bis(trifluoromethane sulfonyl) imide (KTFSI) in mixed dimethoxyethane and dioxolane solution (DOL:DME = 1:1 by volume) as an electrolyte in an argon-filled glovebox. The active mass loading was $\sim 2 \mathrm{mg} / \mathrm{cm}^{2}$. The electrochemical measurements were performed on a LAND system at room temperature. Cyclic voltammetry (CV) was conducted on a VMP-3 multi-channel workstation at a scanning rate of $0.1 \mathrm{mV} / \mathrm{s}$.

\section{Results and discussion}

PAQS was synthesized by a Phillips method. The schematic diagram of PAQS is shown in Figure 1a, which shows two carbonyl groups in one monomer. The PAQS structure was confirmed by XRD and FTIR 
spectrum. The crystalline peaks (Figure 1b) appear at $12^{\circ}, 22^{\circ}$, and $24^{\circ}$, which are consistent with previous literature. However, the peaks are much sharper than the reported ones, indicating a good crystalline structure [18]. SEM imaging shows a large particle size of $>5 \mu \mathrm{m}$ and the $\mathrm{N}_{2}$ sorption results reveal the porous structure of PAQS, where the peak pore size from BJH calculation is $\sim 38 \mathrm{~nm}$ and the Brunauer-Emmett-Teller (BET) surface area is $63 \mathrm{~m}^{2} / \mathrm{g}$ (Figure 1c). The FTIR spectrum is shown in Figure 1d, where all the peaks are consistent with previous works [18]. The $\mathrm{C}=\mathrm{O}$ and $\mathrm{C}=\mathrm{C}$ stretching vibrations of the anthraquinonyl group locate at 1672 and $1568 \mathrm{~cm}^{-1}$, respectively. The peaks at 1410 and $1127 \mathrm{~cm}^{-1}$ correspond to the stretching of the sulfur-disubstituted aromatic ring and the ring-sulfur, respectively. We do obtain anthraquinone-based PAQS by polycondensation.
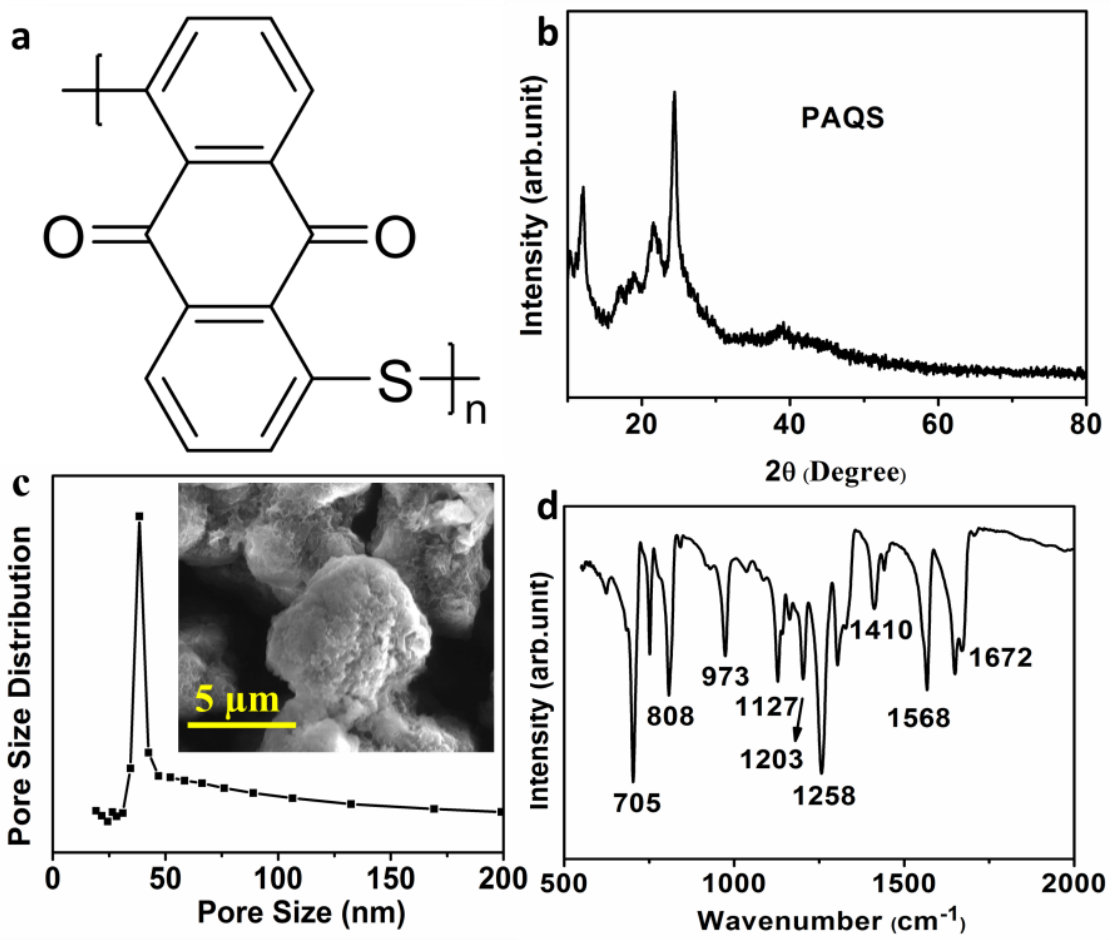

Figure 1. Characterizations of PAQS. (a) Unit molecular structure of PAQS, (b) Wide angle XRD pattern, (c) Pore size distribution (inset is the SEM image) and (d) FTIR spectrum.

First, we assembled PAQS/K cells with the electrolyte of $0.8 \mathrm{M} \mathrm{KPF}_{6}$ in $\mathrm{EC}+\mathrm{DMC}$, which were cycled in the voltage range of 1.5-3.4 V vs. $\mathrm{K}^{+} / \mathrm{K}$ (as shown in Figure 2a). Although the cell shows high discharge 
(potassiation) capacity of $213 \mathrm{mAh} / \mathrm{g}$, its reversible (depotassiation) capacity is only $137 \mathrm{mAh} / \mathrm{g}$. The capacity fades seriously in the subsequent cycles. In contrast, the cell with 0.5 M KTFSI in DOL+DME electrolyte shows impressive initial discharge and charge capacity values of 211 and $190 \mathrm{mAh} / \mathrm{g}$, respectively (Figure 2b). It leads to a high coulombic efficiency of $90 \%$. The subsequent charge/discharge curves almost overlap, especially for the charge curves, indicating good reversibility. Furthermore, the cell using the KTFSI/DOL+DME electrolyte shows much less polarization than the cell with $\mathrm{KPF}_{6} / \mathrm{EC}+\mathrm{DMC}$ electrolyte. Interestingly, the KTFSI/DOL+DME electrolyte shifts the potential of $\mathrm{K}^{+}$ion storage in PAQS to a slightly lower potential compared to the electrolyte of $\mathrm{KPF}_{6} / \mathrm{EC}+\mathrm{DMC}$, particularly with a lack of capacity from 2.4 to $2.8 \mathrm{~V}$ vs. $\mathrm{K}^{+} / \mathrm{K}$. When the cell was cycled between 1.2 and $3.4 \mathrm{~V}$ vs. $\mathrm{K}^{+} / \mathrm{K}$ in the KTFSI/DOL+DME electrolyte, it shows a high reversible capacity of $200 \mathrm{mAh} / \mathrm{g}$ with a first-cycle coulombic efficiency of $85 \%$ (Figure 2c). The charge/discharge curves can be divided to two slopes, where each part is close to $100 \mathrm{mAh} / \mathrm{g}$, corresponding to one $\mathrm{K}^{+}$ion insertion/extraction, and the average potential of the two slopes are 2.1 and $1.6 \mathrm{~V}$ vs. $\mathrm{K}^{+} / \mathrm{K}$. Note that PAQS/Na cells also show the two slopes, leading to a high capacity of $220 \mathrm{mAh} / \mathrm{g}$ [19]. However, PAQS/Li cells exhibit only one slope, which still presents a high capacity of $185 \mathrm{mAh} / \mathrm{g}$ [18]. All the PAQS/alkali metal cells present the insertion/extraction of about two alkali ions. The $\mathrm{K}^{+}$ion storage mechanism in PAQS is indicated in Figure 2e, which is similar with PAQS/Na cells [19].

The CV curves (Figure 2d) also show the two couples of redox peaks, where the initial cathodic peaks are at 1.68 and $1.38 \mathrm{~V}$ vs. $\mathrm{K}^{+} / \mathrm{K}$ and the subsequent cathodic peaks shift to 1.87 and $1.45 \mathrm{~V}$ vs. $\mathrm{K}^{+} / \mathrm{K}$, which are slightly lower than the average galvanostatic discharge potentials for the two slopes, respectively. All the anodic curves in different cycles overlap well, where the peaks locate at the same positions: 2.37 and $1.94 \mathrm{~V}$ vs. $\mathrm{K}^{+} / \mathrm{K}$. The $\mathrm{CV}$ results further confirm the $\mathrm{K}^{+}$storage mechanism in PAQS, which corresponds to two $\mathrm{K}^{+}$ions inserted in two sequential steps. PAQS/Na cells also show two pairs of redox peaks, while the PAQS/Li cells present only one pair of broad redox peaks $[18,19]$. Therefore, the $\mathrm{K}^{+}$storage mechanism in PAQS is similar to that of $\mathrm{Na}$, but not $\mathrm{Li}$. This behavior trend is vastly different from the graphite/alkali metal cells, where 
graphite/Li and graphite/K show similar storage mechanisms, while Na can be barely inserted into graphite (the reversible capacity is only $\sim 35 \mathrm{mAh} / \mathrm{g}$ ) $[5,21,22]$.
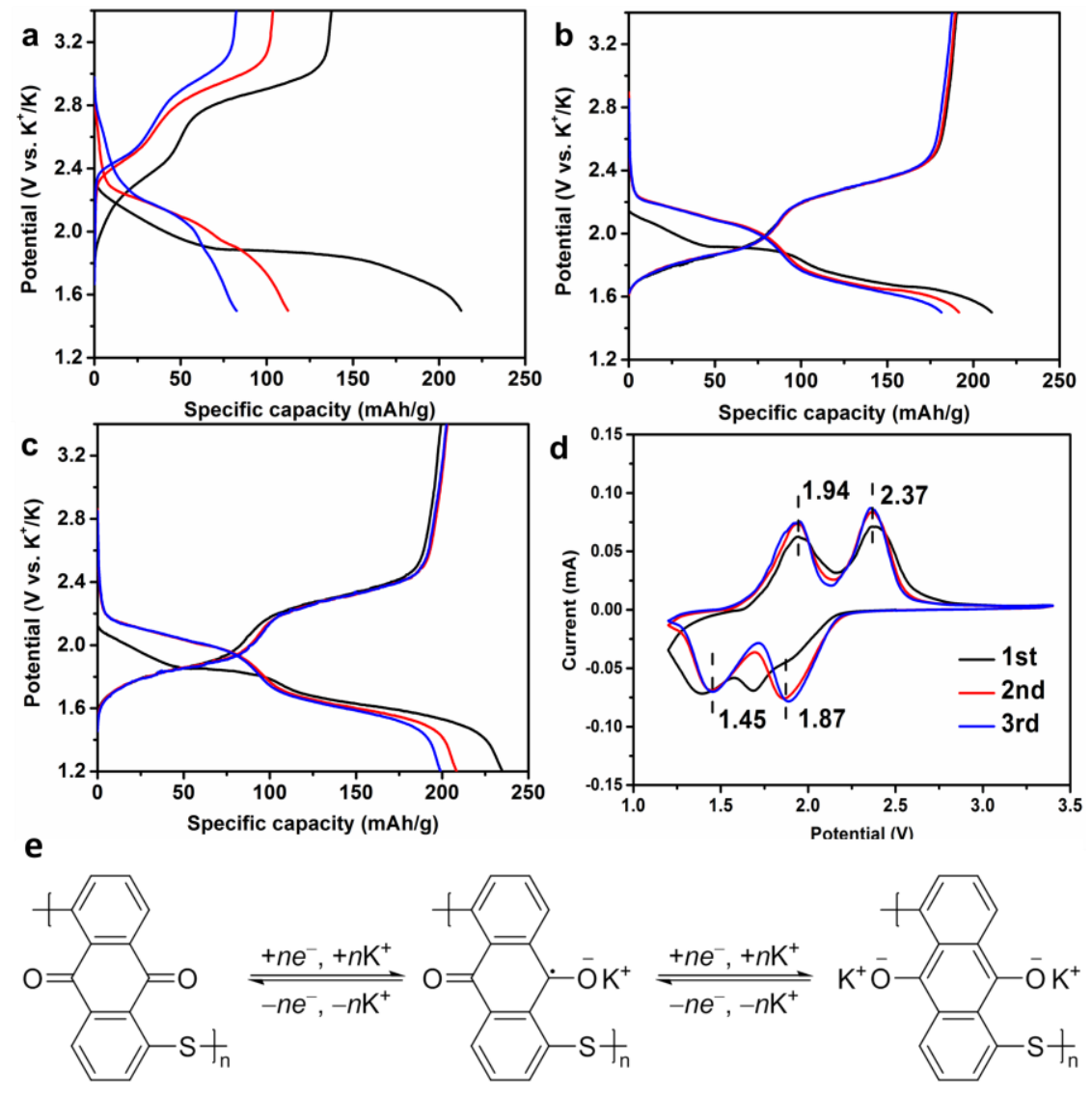

Figure 2. (a) Charge/discharge profiles of $\mathrm{PAQS} / \mathrm{K}$ cells in $\mathrm{KPF}_{6} / \mathrm{EC}+\mathrm{DMC}$ for the initial three cycles between 1.5 and $3.4 \mathrm{~V}$ at a current density of $20 \mathrm{~mA} / \mathrm{g}$, (b) Charge/discharge profiles of PAQS/K cells in KTFSI/DOL+DME for the initial three cycles between 1.5 and $3.4 \mathrm{~V}$ at a current density of $20 \mathrm{~mA} / \mathrm{g}$, (c) Charge/discharge profiles of PAQS/K cells in KTFSI/DOL+DME for the initial three cycles between 1.2 and $3.4 \mathrm{~V}$ at a current density of $20 \mathrm{~mA} / \mathrm{g}$, (d) CV curves of PAQS in KTFSI/DOL+DME for the initial three cycles between 1.2 and $3.4 \mathrm{~V}$ at a scan rate of $0.1 \mathrm{mV} / \mathrm{s}$, (e) A possible redox mechanism of potassium storage in PAQS. 
The cycling performance of PAQS/K cells in KTFSI/DOL+DME electrolyte was investigated, as shown in Figure 3. As displayed in Figure 3a, the PAQS electrode delivers a high reversible capacity of $190 \mathrm{mAh} / \mathrm{g}$ between 1.5 and $3.4 \mathrm{~V}$ vs. $\mathrm{K}^{+} / \mathrm{K}$ at a current density of $20 \mathrm{~mA} / \mathrm{g}, 84 \%$ of its theoretical capacity (for two K-ion insertion/extraction). It also shows a good cycling performance, with capacity retention of $75 \%$ after 50 cycles, which is better than that of the organic molecular solid-PTCDA [14]. Furthermore, the cell exhibits high coulombic efficiency, which is close to $100 \%$ after initial cycles. The cycling performance at a high current density $(200 \mathrm{~mA} / \mathrm{g})$ between 1.5 and $3.4 \mathrm{~V}$ vs. $\mathrm{K}^{+} / \mathrm{K}$ was also investigated. As shown in Figure $\mathbf{3 b}$, the cycling performance is relatively stable but the capacity is low, which might be due to its big particle size (see the inset of Figure 1c). The reversible capacity is $88 \mathrm{mAh} / \mathrm{g}$ in the first cycle, then increases to $106 \mathrm{mAh} / \mathrm{g}$ and finally decreased to $68 \mathrm{mAh} / \mathrm{g}$ after 200 cycles. The mild capacity fading may be attributed to the partial dissolution of PAQS in the electrolyte, where we notice that the separator became dark yellow after 50 cycles.
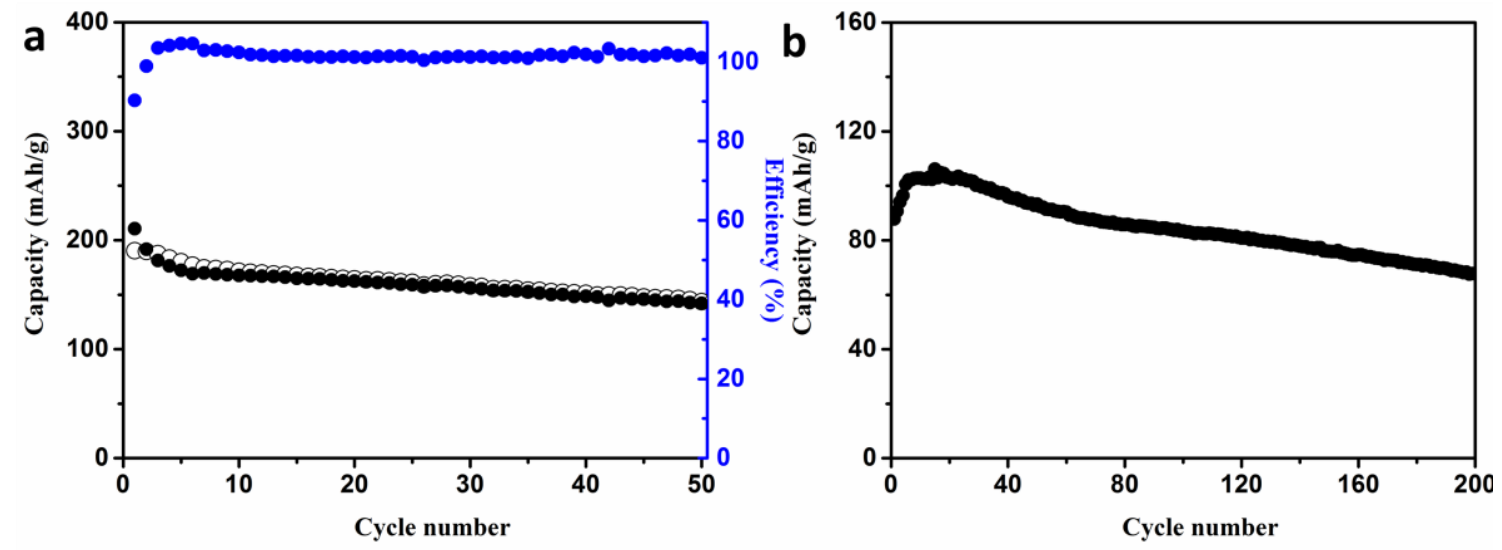

Figure 3. (a) Cycling performance of $\mathrm{PAQS} / \mathrm{K}$ cells between 1.5 and $3.4 \mathrm{~V}$ vs. $\mathrm{K}^{+} / \mathrm{K}$ at a current density of 20 $\mathrm{mA} / \mathrm{g}$; (b) cycling performance of PAQS/K cells between 1.2 and $3.4 \mathrm{~V} \mathrm{~K}^{+} / \mathrm{K}$ at a current density of $200 \mathrm{~mA} / \mathrm{g}$.

\section{Conclusion}

In summary, PAQS was investigated as a KIB cathode material for the first time, which shows a high reversible capacity of $200 \mathrm{mAh} / \mathrm{g}$ in the KTFSI/DOL+DME electrolyte. The corresponding two slopes indicate two K-ion insertion/extraction into and from the PAQS electrode, which is similar with the 
mechanism of $\mathrm{Na}^{+}$insertion into PAQS. The PAQS/K cells show high initial coulombic efficiency (as high as 90\%) and moderate cycling performance. With encouraging performance, PAQS represents a promising candidate cathode material for KIBs. Further studies will focus on improving the cycling stability and rate performance.

\section{Acknowledgements}

X. J. are thankful for the financial supports from National Science Foundation Award No. CBET-1551693. Y. Y. acknowledges financial support from the Office of Naval Research (No. N00014-13-1-0543) and National Science Foundation (CMMI-1400261).

\section{References}

[1] S.W. Kim, D.H. Seo, X. Ma, G. Ceder, K. Kang, Electrode Materials for Rechargeable Sodium-Ion Batteries: Potential Alternatives to Current Lithium-Ion Batteries, Advanced Energy Materials, 2 (2012) 710 $\underline{721 .}$

[2] H. Pan, Y.-S. Hu, L. Chen, Room-temperature stationary sodium-ion batteries for large-scale electric energy storage, Energy \& Environmental Science, 6 (2013) 2338-2360.

[3] N. Yabuuchi, K. Kubota, M. Dahbi, S. Komaba, Research development on sodium-ion batteries, Chemical Reviews, 114 (2014) 11636-11682.

[4] A. Eftekhari, Potassium secondary cell based on Prussian blue cathode, J. Power Sources, 126 (2004) 221$\underline{228 .}$

[5] Z. Jian, W. Luo, X. Ji, Carbon Electrodes for K-Ion Batteries, Journal of the American Chemical Society, 137 (2015) 11566-11569.

[6] X. Ren, Y. Wu, A low-overpotential potassium-oxygen battery based on potassium superoxide, Journal of the American Chemical Society, 135 (2013) 2923-2926.

[7] Q. Zhao, Y. Hu, K. Zhang, J. Chen, Potassium-Sulfur Batteries: A New Member of Room-Temperature

$\underline{\text { Rechargeable Metal-Sulfur Batteries, Inorganic chemistry, } 53 \text { (2014) 9000-9005. }}$

[8] C.D. Wessells, R.A. Huggins, Y. Cui, Copper hexacyanoferrate battery electrodes with long cycle life and high power, Nature communications, 2 (2011) 550. 
[9] C.D. Wessells, S.V. Peddada, R.A. Huggins, Y. Cui, Nickel hexacyanoferrate nanoparticle electrodes for aqueous sodium and potassium ion batteries, Nano letters, 11 (2011) 5421-5425.

[10] Y. Liu, F. Fan, J. Wang, Y. Liu, H. Chen, K.L. Jungjohann, Y. Xu, Y. Zhu, D. Bigio, T. Zhu, C. Wang, In $\underline{\text { situ transmission electron microscopy study of electrochemical sodiation and potassiation of carbon nanofibers, }}$ Nano letters, 14 (2014) 3445-3452.

[11] S. Komaba, T. Hasegawa, M. Dahbi, K. Kubota, Potassium intercalation into graphite to realize highvoltage/high-power potassium-ion batteries and potassium-ion capacitors, Electrochemistry Communications, $\underline{60(2015) 172-175 .}$

[12] W. Luo, J. Wan, B. Ozdemir, W. Bao, Y. Chen, J. Dai, H. Lin, Y. Xu, F. Gu, V. Barone, L. Hu, Potassium Ion Batteries with Graphitic Materials, Nano letters, 15 (2015) 7671-7677.

[13] Y. Chen, W. Luo, M. Carter, L. Zhou, J. Dai, K. Fu, S. Lacey, T. Li, J. Wan, X. Han, Organic electrode for non-aqueous potassium-ion batteries, Nano Energy, 18 (2015) 205-211.

[14] Z. Xing, Z. Jian, W. Luo, Y. Qi, C. Bommier, E.S. Chong, Z. Li, L. Hu, X. Ji, A perylene anhydride crystal as a reversible electrode for K-ion batteries, Energy Storage Materials, 2 (2016) 63-68.

[15] J. Wu, X. Rui, G. Long, W. Chen, Q. Yan, Q. Zhang, Pushing up lithium storage through nanostructured polyazaacene analogues as anode, Angewandte Chemie International Edition, 54 (2015) 7354-7358. [16] P.-Y. Gu, J. Zhang, G. Long, Z. Wang, Q. Zhang, Solution-processable thiadiazoloquinoxaline-based donor-acceptor small molecules for thin-film transistors, Journal of Materials Chemistry C, 4 (2016) 3809$\underline{3814 .}$

[17] J. Wu, X. Rui, C. Wang, W.B. Pei, R. Lau, Q. Yan, Q. Zhang, Nanostructured Conjugated Ladder Polymers for Stable and Fast Lithium Storage Anodes with High-Capacity, Advanced Energy Materials, 5 (2015) 1402189-1402194.

[18] Z. Song, H. Zhan, Y. Zhou, Anthraquinone based polymer as high performance cathode material for rechargeable lithium batteries, Chem. Commun., (2009) 448-450.

[19] W. Deng, X. Liang, X. Wu, J. Qian, Y. Cao, X. Ai, J. Feng, H. Yang, A low cost, all-organic Na-ion battery based on polymeric cathode and anode, Scientific reports, 3 (2013). 
[20] J. Bitenc, K. Pirnat, T. Bančič, M. Gaberšček, B. Genorio, A. Randon-Vitanova, R. Dominko, Anthraquinone-Based Polymer as Cathode in Rechargeable Magnesium Batteries, ChemSusChem, 8 (2015) 4128-4132.

[21] T. Ohzuku, Y. Iwakoshi, K. Sawai, Formation of Lithium-Graphite Intercalation Compounds in Nonaqueous Electrolytes and Their Application as a Negative Electrode for a Lithium Ion (Shuttlecock) Cell, Journal of The Electrochemical Society, 140 (1993) 2490-2498.

[22] R. Asher, S. Wilson, Lamellar compound of sodium with graphite, Nature, 181 (1958). 
Graphical abstract

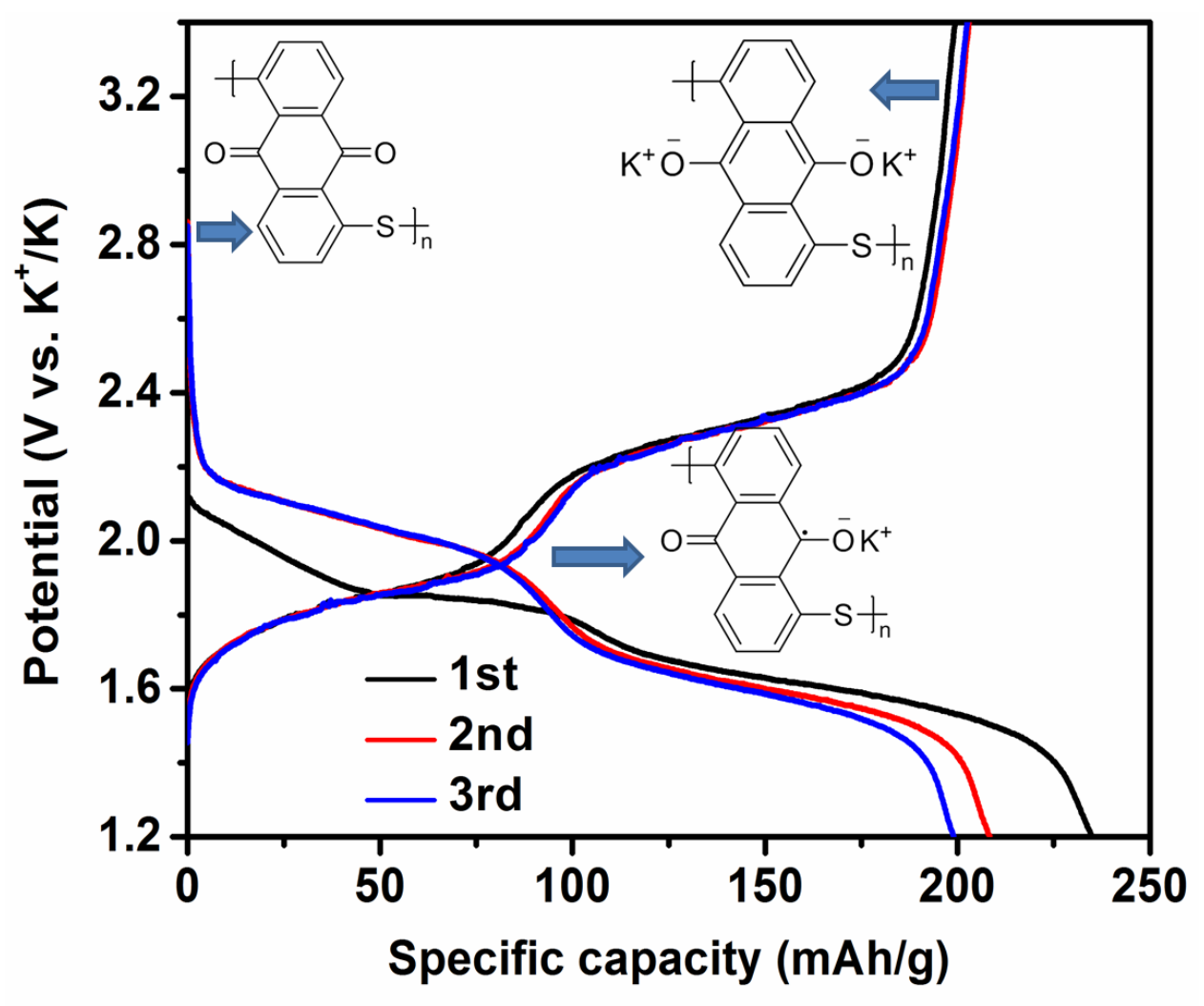

